\title{
Rural development in small mountainous settlements: case study of Bojnord region, North-eastern part of Iran
}

\author{
M. Taleshi \\ Payam Noor University, Iran
}

\begin{abstract}
More than $47 \%$ of the rural settlements (32147 units) in Iran have been spatially categorized as mountainous, which are characterized with their small size of population. This means that more than $85 \%$ of these settlements (27385 units) have a population of less than 100 households. Though lack of water and soil resources have caused these small settlements to be dispersed along the country as small villages, these have unique spatial functions, i.e. the stabilization of population and exploitation of the limited and scattered natural resources.

The mountainous rural settlements of the area under study have the same environmental-ecologic conditions as discussed above. This study has proved that, during the last two decades, the destructive processes governing the ecologic conditions of the area have reached their highest level and severely worsened the soil erosion and destruction of many pastures. Thus, in 1981 only $15 \%$ of these small settlements experienced unsustainable conditions, but this increased to $57 \%$ by the year 2001 .

Therefore, in order to keep up the functional role of the mountainous settlements in micro and macro-spatial-levels, we need first of all to drastically change our approaches to Strategic Plans and so to development procedures at local, regional and national levels. Thus, through supporting and encouraging the rural households, sustaining the small mountainous settlements could be possible! On the other hand, the participative efforts of the villagers in the establishment of NGO must be widely promoted. Thus, establishment and support of the informal popular institutions in different parts can lead to control of the destruction of natural sources. Moreover, the realization and guarantee of the stable production and income and the right change to the provision of common services can result in stable rural development in mountainous areas.

Keywords: rural development, instability, small settlements, participation, nongovernmental organizations.
\end{abstract}




\section{Introduction}

In the 21st charter of the 13th chapter of the Rio Conference damageable mountainous perimeters were considered by scientists, especially natural resources, economists, geographers and other related researchers.

Following this scientific event, the United Nation Organization named the year 2002 as the International Year of Mountains.

In the ecological environment of mountains, rural settlements, especially small ones, are set in unstable conditions, and this instability will affect rural development. In this way, an excess of unstable conditions will have a direct effect on the process of poverty and social justice.

Therefore, the process of instability in small mountainous settlements in the Aladagh region at the North-east of Iran as a mountainous region is considered in this paper, followed by recommendation of appropriate strategies for rural development in these settlements.

\section{Region under study}

Aladagh region lies at the North-east of Iran (between $37^{\circ}, 15^{\prime}$ to $37^{\circ}, 39^{\prime}$ North latitudes and $56^{\circ}, 57^{\prime}$ to $57^{\circ}, 35^{\prime}$ East longitudes).

The area is 150400 hectares with 69 mountainous settlements with a population of 55737 .

The most important ranges of the region are;

Qarabolagh with 1517 meters height,

Shalakh with 1875 meters height, at the North of the region,

Sefid bodagh 2459 m, Qaraghoy 2227 m, Ajan and Shimily $2150 \mathrm{~m}$, Namazkhaneh $2455 \mathrm{~m}$.

\section{Assessment method of mountainous settlements instability}

Considerations and assessments of various available approaches in sustainability for different aspects such as environmentally sustainable development, economic sustainable development, cultural sustainable development, physical-spatial sustainable development underwent a final selection.

In this approach economic and environmental-economic, socio-cultural and physical-spatial structures and relations were considered.

In this study, relations between sustainability and non-sustainability on rural settlements were considered through a series of effective factors.

\section{Studies of effective factors}

These included:

* Environmental/Ecological factors:

1) Settlement elevation

2) Water balance 
3) Soil erosion

4) Force major damages (flood, earthquake)

5) Pasture demolition (Crown coverage amount)

* Socio-economical factors:

1) Immigration

2) Literate ration

3) Employment percentage

4) Population density

5) Supporting load

6) Income per capita

7) Agricultural lands distribution

8) Percentage enjoyment of rural roads

* Physical-spatial factors:

1) Average monthly trips to city

2) Average distance between settlements and city

3) Percentage of rural owners residing in city

4) Percentage of enjoying services by the people

* Official planning factors:

1) Ratio between infrastructure credits and total credits of the village

2) Ratio between production affairs and total credits of the village

3) Ratio between social affairs and total credits of the village

In this way, all settlements in the region were considered in three categories, non-sustainable, sustainable and semi-sustainable, and finally non-sustainability conditions were studied through statistical models and correlation equations.

\section{Assessment results of non-sustainability conditions in rural settlements}

According to studies on environmental-ecological factors, results show that for non-sustainability in small settlements based on geological factors (land slides and quakes), more than $65 \%$ of small settlements lie on unstable geological formations and $58 \%$ of settlements have non-sustainable conditions from a land slide point of view. On the other hand, $57 \%$ of small rural settlements are nonsustainable considering water resources.

Soil erosion factor as a basic factor in demolishing of renewable resources in small settlements shows that in the year 1981 only $15 \%$ of these settlements had non-sustainable conditions, while as in the year 2001 this amount increased to $57 \%$.

The demolition of landscapes in small settlements shows that in the year $1981,25 \%$ had non-sustainable conditions, whereas in 2001 it increased to $61 \%$.

Socio-economic factors in small mountainous settlements always show that annually $2.7 \%$ of rural employees are decreased and the unemployment rate increased annually by $6.8 \%$. 
The results of income and wealth distribution show that, in 1981 , only $20 \%$ of the rural population did not own any land, while as in 2001 this amount increased to $50 \%$. On the other hand, the results recommend that only $10 \%$ of the population have $50 \%$ of resources and wealth and the remaining $90 \%$ of the population have only $50 \%$ of income.

Average income of each rural family residing in Aladagh region's small settlements is less than $100 \$$, which in comparison with other regions of the country and South-east of Asia, and even China is so little.

Considerations on physical-spatial factors show that the distance between these settlements and 2nd grade urban centers is $25 \mathrm{~km}$ and more than $80 \%$ of these settlements have dirt access roads. On the other hand, $90 \%$ of these settlements have non-sustainable conditions of welfare facilities.

More than $87 \%$ of residential buildings are made of low quality and low durability material, such as sun-dried bricks, woods and mud, intensifying its damageability.

After lots of statistical considerations, it has been approved that, basically, some parts of the effective forces had an immediate (direct) affect on nonsustainability of small settlements. These immediate factors include six key factors, such as amount of soil erosion, pasture demolition, water balance, force major damages per capita, agricultural lands distribution and income per capita.

Except water balance, the other five forces have a direct relation with nonsustainability of small mountainous settlements, so that, with increase in the amount of any immediate factors, the amount of non-sustainability processes increases basically.

The second group of forces and effective factors have indirect rule. In fact, these factors do not affect directly the non-sustainability, but affect the six main factors, causing non-sustainability on small rural settlements.

The complex equations of direct forces with indirect factors are identified by two equations, reverse (correlation coefficient zero to -1) and direct (correlation coefficient zero to +1$)$.

According to the final analysis, circumstances of equations and effective forces have been organized.

Physical-spatial factors are in the 1st line, Socio-economical factors in the 2nd line, and enjoyment of services factor as transition factor between two other groups of factors, 3rd line consists of planning factors, like civil credits, and $4^{\text {th }}$ line consists of elevation factors to consider the behavior and relation between effective factors on elevation conditions of rural settlements. Statistical analysis of physical-spatial factors showed that, as the distance between the settlement and the city increases, there is more intention to migrate by the owner. On the other hand, the distance between settlement and the city has a reverse connection with average monthly trips by villagers, because as the distance decreases, the trips to the city increase.

The effects of these factors (physical-spatial) on direct factors are such that the percentage of owners in the city has a reverse connection on water balance. This means, as the number of owners residing in the city decreases, water 
balance acts better. More clearly, a reverse connection between migration of owners and water balance can be approved.

In socio-economical factors, employment rate has a reverse connection with enjoyment of services, because increase in the provision of services in mountainous settlements will decrease the employment percentage.

Therefore, present service providing regulations in mountainous settlements do not increase employment facilities.

Enjoyment of services has a reverse connection with immigration. Service facilities in mountainous settlements did not prevent the immigration of villagers, and more importantly, the enjoyment factor of rural roads shows a reverse connection with per capita income of villagers as an increase in enjoying rural roads per capita income of villagers' decreases. More clearly, there are meaningful connections between enjoyment of rural roads, employment percentage and enjoyment of services with direct factors.

Always, an increase of rural roads and the enjoyment of services coefficient per capita income decreases, and this affects directly the non-sustainability of settlements.

In governmental credits, the amount of production credits is in reverse connection with pasture demolition.

In fact, as the amount of production credits in mountainous settlements decreases, more pastures are demolished. On the other hand, this factor is in reverse connection with per capita force major damages.

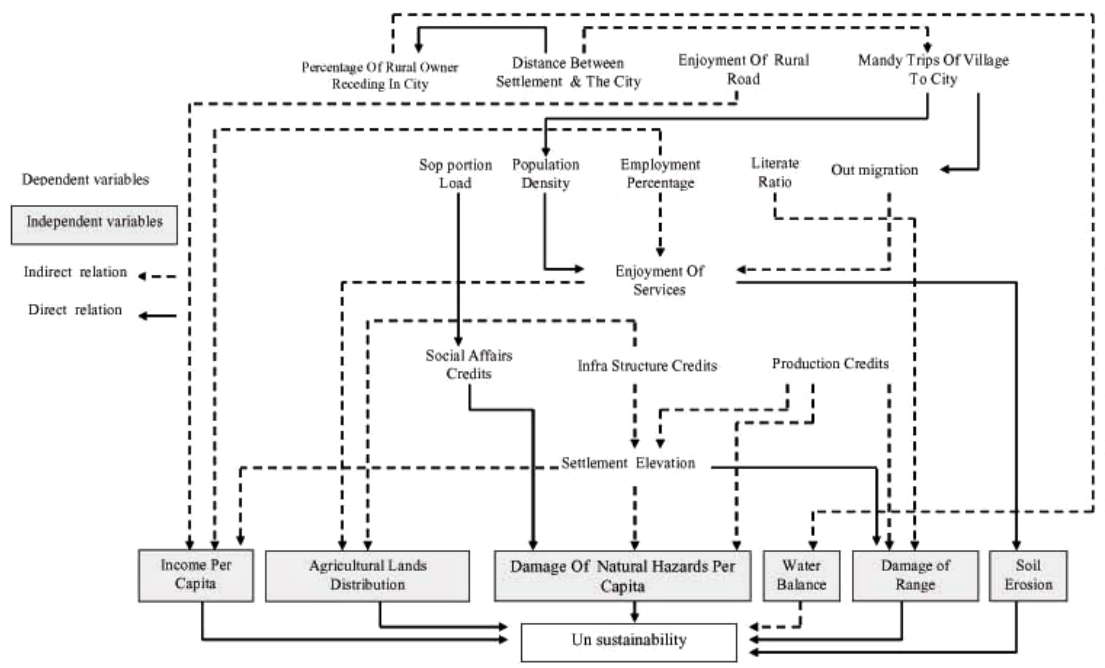

Figure 1: Applied patterns of relation between effective variables on unsustainability. 
Therefore, the complex of ruling factors show that socio-economical factors affected from the country's planning program (inattention to small settlements and tendency towards cities) had great effects on demolition of renewable resources (such as water, soil and pasture), resulting in a decrease of ecological capacities.

This decrease caused, in a way, the decrease of bearing coefficient and population stabilization in small settlements.

\section{Rural development plans}

To leave partially non-sustainable conditions, all aspects of rural development should be considered uniformly and epidemically.

More clearly, to access an epidemical rural development in mountainous settlements, the following pivots should be considered properly and effectively:

- Appropriate protection and operation of basic resources.

- Education of population concerning local issues in mountainous settlements.

- Appropriate foundation for strengthening and extension of participation mentality (active, continuous and epidemical participation).

- Increase in profitability of present economical facilities and creating spaces for new economical activities.

- Growing living quality levels in mountainous settlements.

- Modification and regulation of physical-spatial network of mountainous settlements to enjoy proper facilities and services.

Therefore, to compile a sustainable planning regulation in mountainous settlements and by scrutinizing considered pivots (relying on sustainable development from physical-spatial point of view), the most important rural sustainable development plans are described:

Ecologically

$\checkmark \quad$ Changing low efficiency dry farms into pastures

$\checkmark \quad$ Occasional pile irrigation

$\checkmark \quad$ Preservation and protection preservation

$\checkmark \quad$ Mechanical operations (reservoir dams, etc.)

Socio-habitat

$\checkmark \quad$ Creation and development of proper training-cultural activities

$\checkmark \quad$ Strengthening the villager's active and continuous role in participation

$\checkmark \quad$ Establishing appropriate private (non-governmental) organizations

$\checkmark \quad$ Growing living quality satisfaction in villagers (sanitary, clinical, Economically consumption pattern facilities)

$\checkmark \quad$ Modification and improvement of revenue methods from basic resources (increase in profitability)

Making equal opportunities for all villagers to access credits and financial facilities (distribution of civil credits)

Transformation of economical structures to persuade nongovernmental and private sector participation 
$\checkmark \quad$ Creating variety in economical activities

$\checkmark \quad$ Increasing employment opportunities for non-owners in nonPhysical-Spatially agricultural and natural resources activities

$\checkmark \quad$ Reclamation of residential buildings, facilities and social welfares

Sounding appropriate physical-spatial relations between rural and urban settlements

Leveling of rural settlements to make balanced and sustainable relations among the settlements.

\section{References}

[1] Barow, C.G., (1955), sustainable development: Concept, Value and Practice, Journal of Environment, Vol.14;

[2] Hamilton, L.S. 1995. The productive role of mountain forests. In: Mountain at Risk (N.J.R. Allan, ed.) Manohar, New Delhi, pp.49-69

[3] Hanley, N, (1997) Macroeconomic Measures of sustainability: A survey and A Synthesis. Discussion papers in Ecological Economics 97/3, Deportment of Economics, University of Stirling, Stirling. UK

[4] Harris. M.J (2000) Basic Principles of sustainable development. Tufts. Univer. U.S.A

[5] Hicks (1946) sustainable development, University London press

[6] Jackson, T. and Marks, N (1994) Measuring Sustainable Economic Welfare: A pilot Index. Stockholm environment Institute / New economics foundation, Stockholm.

[7] Jansky Libor (2002) Global mountain research for sustainable development, UN University.

[8] UNDP (2002) Report Word Summon Development, Johannesburg. 